\title{
3 Research Square

\section{Role of Positive Mental Health in Reducing Fears related to COVID-19 and General Anxiety Disorder in Khyber Pakhtunkhwa, Pakistan}

Qaisar Khalid Mahmood

International Islamic University Islamabad

Malik Muhammad Sohail

Higher Education Department Punjab

Waheed Ahmad Qureshi

Anadolu Üniversitesi Yeşiltepe

Rubeena Zakar

University of the Punjab

Florian Fischer ( $\nabla$ florian.fischer1@charite.de)

Institute of Public Health, Charité - Universitätsmedizin Berlin

Research Article

Keywords: COVID-19, SARS-CoV-2, Corona, Pakistan, Mental health, Quality of life

Posted Date: April 26th, 2021

DOI: https://doi.org/10.21203/rs.3.rs-430599/v1

License: (9) This work is licensed under a Creative Commons Attribution 4.0 International License.

Read Full License 


\section{Abstract}

Background: The outbreak of the novel coronavirus disease (COVID-19) has posed multiple challenges to healthcare systems. Evidence suggests that mental well-being is badly affected due to compliance with preventative measures in containing the COVID-19 pandemic. This study aims to explore the role of positive mental health (subjective sense of wellbeing) to cope with fears related to COVID-19 and general anxiety disorder in the Pashtun community in Pakistan.

Methods: A cross-sectional survey was conducted among 501 respondents from Khyber Pakhtunkhwa participating in an online-based study. We performed correlational analysis, hierarchical linear regression and structural equational modeling (SEM) to analyze the role of mental health in reducing fears and general anxiety disorder.

Results: The results of the SEM show that positive mental health has direct effects in reducing the fear related to COVID-19 $(\beta=-0.244, p<0.001)$ and general anxiety $(\beta=-0.210, p<0.001)$. Fears of COVID-19 has a direct effect on increasing general anxiety $(\beta=0.480)$. In addition, positive mental health also has an indirect effect $(\beta=-0.117, p<0.001)$ on general anxiety $\left(R^{2}=0.32, p<0.001\right)$ through reducing fear of coronavirus.

Conclusion: Based on these findings, there is a need to develop community health policies emphasizing on promotive and preventive mental health strategies for people practicing social/physical distancing.

\section{Background}

The COVID-19 pandemic has generated a wide range of feelings, thoughts and reactions worldwide [1]. From the beginning, it has shown a fastly increasing mortality rate, creating unprecedented fears among the public [2]. Observing an extremely rapid infection rate, the high mortality along with an 'infodemic' makes people extremely worried about COVID-19 [3, 4]. Undoubtedly, the media has played an important role in encouraging preventive behavior [5]. However, on the other hand, excessive media reporting has created an extremely stressful situation worldwide. Such a large-scale outbreak may be followed by panic, fear, suspicion and stigma [6]. In the wake of this pandemic, mental health has become an emergent global challenge. Psychological distress and anxiety have been experienced by survivors during epidemics in recent years [7-9]. Similar experiences of mental health disorders - such as obsessioncompulsion, anxiety, hostility, phobic anxiety, paranoid ideation and psycho-trauma - were shared either by survivors of Ebola and Zika outbreaks in Africa [10-12].

Fear of contracting the COVID-19 infection has been observed among people worldwide [13, 14]. In such a situation, this fear may increase the intensity of the disease itself [15]. During such a large-scale health crisis, individuals may not make rational decisions regarding behavior changes in order to evade any viral contagion [16]. The World Health Organization (WHO) has highlighted a substantial need for psychological interventions during the COVID-19 outbreak to avoid any further crisis of compromised 
mental health for those suffering from the infection itself, and for those who are in self-isolation or quarantined [17].

Until a few years ago, the focus of mental health professionals was on negative mental health issues, such as anxiety, depression, delusions, phobias and obsessions. Little attention has been paid to positive mental health indicators, such as happiness, hope and resilience. One of the pioneers of positive psychology, George Vaillant, revealed that a large majority of psychiatric content focuses merely on negative mental health issues. Vaillant noted that the clinical bible of psychiatry and clinical psychology, the Comprehensive Textbook of Psychiatry, has 500,000 lines of text with thousands of lines on anxiety and depression, while hundreds of lines on terror, shame, guilt, anger, and fear [18]. However, there are only five lines on hope, one line on joy, and not a single line on compassion, forgiveness, or love [19]. In recent years, new evidence-based psychology has emerged that pays attention to positive emotions and positive mental health [20]. Many recent studies emphasize the significance of positive emotions in mental health and well-being [21].

Positive mental health revolves around positive emotions, feelings and functioning, which help individuals cope with the normal stresses of life, work productively and fruitfully, and to contribute towards the improvement of community life by using their own abilities [22]. Positive mental health has been conceptualized in numerous different ways. Its conceptualization may consist of the presence of multiple human strengths, the dominance of positive emotions, high socio-emotional intelligence, subjective well-being and resilience [18]. It signifies a significant a shift from defining mental health as the mere absence of mental illness to a vaster emphasis on optimal psychological functioning and/or a fulfilling experience of life [23]. Separating positive mental health from mental illness represents two separate continua which cannot elucidate the appropriate solution to mental health challenges [24]. Increasing evidence suggests that high levels of positive mental health reduce the propensity of mental illness [25]. It may help to prevent and treat psychopathology [26].

Globally, a plethora of studies [27-30] have focused on negative mental health conditions caused by the COVID-19 pandemic. Until now, studies focusing on positive mental health to cope with COVID-19 related anxiety, fears and stress have rarely been found. Indeed, a prevention and treatment approach to mental illness has not worked well in the past [31]. Therefore, we need to shift our attention to positive mental health, positive emotions and positive functioning. The present study aims to investigate the role of positive mental health in reducing fears and anxiety during the COVID-19 pandemic. Based on the literature, we hypothesize that people who use positive mental health strategies are more likely to handle their fears and anxiety during the pandemic adequately.

\section{Methods}

\section{Study setting}


With a population of 35.5 million, Khyber Pakhtunkhwa is the third largest province of Pakistan; it is located in the northwestern region of the country [32]. Even after getting the provincial autonomy, the healthcare system of Khyber Pakhtunkhwa is in the process of development. Therefore, the region is unable to endure the influx of patients in case of medical emergency [33], which is visible in high numbers of COVID-19 cases and deaths [34]. An increasing number of COVID-19 cases can exacerbate psychological challenges and complications for the population. Ravaged by military operation, terrorist attacks and population displacement within the last two decades, the Khyber Pakhtunkhwa province only has few mental health facilities.

\section{Study design and data collection}

An online-based cross-sectional study was conducted during a two weeks' period from May 10 to 23 May, 2020. We developed a questionnaire based on validated instruments and shared a hyperlink with the respondents through various social media platforms, such as Facebook, Linkedln, and WhatsApp. This study was conducted in Khyber Pakhtunkhwa, one of the most vulnerable provinces of Pakistan due to its geographical typography and poor health infrastructure. In total, 501 persons successfully completed this survey.

\section{Ethical approval and consent to participate}

The respondents were briefed about the purpose of the study. Every participant provided online-based informed consent before filling the questionnaire. The respondents voluntarily participated in this study and did not receive any incentive in this regard. The researchers assured anonymity and confidentiality of participants' data. The study was approved by Ethical Review Committee of the Department of Sociology, International Islamic University Islamabad (No. 002-20).

\section{Measuring instruments}

Positive mental health. The 'Positive Mental Health Scale' (PMH-scale) [35] was used to assess the holistic concept of positive emotionality related to positive mental health. This scale consists of nine items (e.g. "I am often carefree and in good spirits", "I manage well to fulfill my needs", and "I feel that I am actually well-equipped to deal with life and its difficulties"). These items were rated on a Likert scale from 1 (not true) to 4 (true). The reported value of Cronbach's alpha was 0.842 indicating good internal consistency.

Fear of COVID-19. Recently, the 'Fear of COVID-19 Scale' (FCV-19S) has been developed to assess the fear of COVID-19 [15]. The FCV-19S is a 7-item scale (e.g. "It makes me uncomfortable to think about Corona" and "I cannot sleep because I worry about getting Corona") measured on a 5-point Likert scale. A fivepoint Likert-scale ( $1=$ "strongly disagree" to $5=$ "strongly agree") is used to report the responses of the respondents [15]. This scale has been developed in English language, but has been validated in other languages as well [36-38]. Mahmood and his colleagues have validated the Urdu version of FCV-19S in Pakistan [39]. The scale was reliable, indicated by Cronbach's alpha value of 0.872 . 
Preventive behavior related to COVID-19. According to available knowledge regarding COVID-19 and the recommendations provided by the WHO [17], Mahmood et al. [39] developed seven statements to measure preventive behavior related to COVID-19 (e.g. "I regularly wash my hands for twenty seconds" and "I maintain social/physical distancing while meeting others"). These items were measured on a 5point Likert scale ( $1=$ "strongly disagree" to $5=$ "strongly agree"). The scale was highly reliable $(a=0.846)$.

Generalized anxiety disorder. The Generalized Anxiety Disorder (GAD) questionnaire was developed to measure anxiety disorders [40]. This scale consists of seven items. These items describe a number of the most salient diagnostic features of GAD (i.e., feeling nervous, anxious, or on edge, and worrying too much about various things). Items are rated on a 4-point Likert-type scale ( $1=$ "not at all" to $4=$ "almost every day") with high reliability $(a=0.892)$.

\section{Statistical analysis}

All analyses were conducted with IBM SPSS Statistics 21. Descriptive statistics were used to report the sample characteristics. Measures of central tendency (mean and standard deviation [SD]) and measures of distribution (skewness and kurtosis) were calculated with respect to each item. Cronbach's alpha coefficient ( $\mathrm{a}$ ) and correlation matrix were calculated. We performed a multiple linear regression model by using a hierarchal method to analyze factors contributing to general anxiety disorder. Finally, path analysis via structural equational modelling (SEM) was conducted. AMOS software was used for this purpose. Goodness of fit was assessed according to the following criteria: goodness of fit index (GFI > $0.90)$, comparative fit index $(\mathrm{CFI}>0.90)$, root mean square residual $(\mathrm{RMSR}<0.08)$, and root mean square error of approximation (RMSEA $<0.08)$. Direct and indirect effects were also calculated.

\section{Results}

\section{Descriptive analyses}

Out of 501 respondents, more than half (58.5\%) were male and approximately $61 \%$ living in urban areas. Most participants (54.5\%) belonged to the $26-50$ years age group, followed by $38.9 \%$ who were aged up to 25 years. Most of the respondents were either graduates (41.5\%) or postgraduates $(46.9 \%)$. The study population had an almost equal representation of unmarried and married people, and more than half of the respondents $(56.7 \%)$ were unemployed.

In Table 1, the measures of central tendency and distribution for study variables are presented. The findings show that the respondents had high average scores of positive mental health and preventive behavior. In addition, they had moderate average scores of fears of COVID-19 and general anxiety disorder. The distribution of scales can be considered normal if the values of skewness and kurtosis range between \pm 2.0 [41]. The results show that all the scales were normally distributed, except general anxiety disorder, because the value for skewness was higher than 2.0. 
Table 1

Psychometric properties of study variables $(\mathrm{n}=501)$

\begin{tabular}{|lllllll|}
\hline Variables & $\begin{array}{l}\text { Number of } \\
\text { items }\end{array}$ & Mean & SD & Kurtosis & Skewness & $\begin{array}{l}\text { Cronbach's } \\
\text { alpha }\end{array}$ \\
\hline Positive mental health & 9 & 34.98 & 4.66 & -0.184 & 0.857 & 0.842 \\
\hline Fear of COVID-19 & 7 & 18.57 & 5.572 & 0.251 & 0.066 & 0.872 \\
\hline Preventive behavior & 7 & 27.16 & 6.021 & -0.801 & -0.002 & 0.846 \\
$\begin{array}{l}\text { General anxiety } \\
\text { disorder }\end{array}$ & 7 & 10.33 & 4.618 & 1.752 & 2.791 & 0.892 \\
\hline
\end{tabular}

\section{Bivariate analysis}

A correlational analysis (Table 2) was conducted to observe the relationships among study variables. The findings show that positive mental health has a negative and significant relationship with fear of COVID$19(r=-0.228, p<0.01)$ and general anxiety disorder $(r=-0.277, p<0.01)$. Positive mental health also has a positive and significant association with preventive behavior $(r=0.122, p<0.01)$. In contrast, fear of COVID-19 was significantly positively correlated with general anxiety disorder $(r=0.450, p<0.01)$. These findings indicate that positive mental health could reduce fear of COVID-19 and general anxiety disorder, whereas fear of COVID-19 could increase general anxiety disorder among study respondents.

Table 2

Correlation matrix of study variables $(\mathrm{n}=501)$

\begin{tabular}{|lllll|}
\hline Variables & $P M H$ & $F C V$ & $P B$ & $G A D$ \\
\hline Positive mental health (PMH) & 1 & $-0.228^{\star \star}$ & $0.122^{* \star}$ & $-0.277^{\star \star}$ \\
\hline Fear of COVID-19 (FCV) & - & 1 & $0.328^{\star \star}$ & $0.450^{* \star}$ \\
\hline Preventive behavior (PB) & - & - & 1 & $0.132^{\star *}$ \\
\hline General anxiety disorder (GAD) & - & - & - & 1 \\
\hline ** Significant at the 0.01 level (2-tailed). & & & \\
\hline
\end{tabular}

\section{Hierarchical linear regression}

A hierarchical linear regression was conducted to indicate factors contributing to general anxiety disorder (Table 3). The findings of model 1 show that positive mental health reduces general anxiety among the respondents $\left(\beta=-0.277, R^{2}=0.075, F=41.602, p<0.001\right)$. In model 2 , fear of COVID-19 and preventive behavior was added along with positive mental health to predict general anxiety. The results indicate that positive mental health reduces general anxiety $(\beta=-0.189, p<0.001)$, whereas fear of COVID-19 $(\beta=0.399$, $p<0.001)$ increases it among the respondents $\left(R^{2}=0.236, F=51.048, p<0.001\right)$. However, preventive behavior does not explain the general anxiety among the respondents $(\beta=0.025, p=0.561)$. 
Table 3

Results of linear regression predicting general anxiety disorder $(n=501)$

\begin{tabular}{|c|c|c|c|c|c|c|c|}
\hline Model & Variables & $B$ & $S E$ & $\beta$ & $t$ & $95 \% \mathrm{Cl}$ & $p$ \\
\hline \multirow[t]{3}{*}{1} & (Constant) & 19.944 & 1.503 & & 13.268 & $16.990-22.897$ & $<0.001$ \\
\hline & Positive mental health & -0.275 & 0.043 & -0.277 & -6.450 & $-0.358--0.191$ & $<0.001$ \\
\hline & \multicolumn{7}{|c|}{$R^{2}=0.075, F=41.602, p<0.001$} \\
\hline \multirow[t]{5}{*}{2} & (Constant) & 10.232 & 1.694 & & 6.039 & $6.903-13.562$ & $<0.001$ \\
\hline & Positive mental health & -0.187 & 0.041 & -0.189 & -4.584 & $-0.268--0.107$ & $<0.001$ \\
\hline & Fear of COVID-19 & 0.331 & 0.036 & 0.399 & 9.211 & $0.260-0.401$ & $<0.001$ \\
\hline & Preventive behavior & 0.019 & 0.033 & 0.025 & 0.582 & $-0.045-0.083$ & 0.561 \\
\hline & $R^{2}=0.236, F=51.048, p$ & $<0.001$ & & & & & \\
\hline
\end{tabular}

\section{Structural equational modeling}

Bearing in mind the results of the hierarchal linear regression, it can be concluded that positive mental health reduced general anxiety among the respondents. However, there is a need to investigate the role of positive mental health in controlling the fear of COVID-19. Moreover, correlational analysis indicates that there is a negative relationship between positive mental health and fear of COVID-19. To examine the interplay among positive mental health, fear of COVID-19 and general anxiety, we performed structural equational modeling by assuming positive mental health as an independent variable, general anxiety as a dependent variable and fear of COVID-19 as a mediating variable. The results show that all fit indices are within an acceptable range $\left(X 2_{(219, n=501)}=502.89, p<0.05 ; R M S R=0.046 ; \mathrm{RMSEA}=0.051 ; \mathrm{GFI}=0.921\right.$; $\mathrm{CFI}=0.946)$.

Positive mental health had direct effects in reducing the fear of COVID-19 $(\beta=-0.244, p<0.001)$ and general anxiety $(\beta=-0.210, p<0.001)$. Fear of COVID-19 had a direct effect on increasing general anxiety $(\beta=0.480, p<0.001)$. In addition to the direct effect of positive mental health on general anxiety, it also had an indirect effect $(\beta=-0.117, p<0.001)$ via fear of COVID-19 on general anxiety. Therefore, it can be concluded that positive mental health reduces fear of COVID-19 and general anxiety among the respondents (Table 4, Fig. 1). 
Table 4

Direct and indirect effects of positive mental health $(n=501)$

\begin{tabular}{|c|c|c|c|}
\hline Model & $\begin{array}{l}\text { Direct effects } \\
\text { (ß) }\end{array}$ & $\begin{array}{l}\text { Indirect effects } \\
\text { (ß) }\end{array}$ & $\begin{array}{l}\text { Total effects } \\
\text { (ß) }\end{array}$ \\
\hline $\mathrm{PMH} \rightarrow \mathrm{FCV}$ & $-0.244^{\star \star \star}$ & & $-0.244^{\star \star \star}$ \\
\hline $\mathrm{PMH} \rightarrow \mathrm{GAD}$ & $-0.210^{\star \star \star}$ & $-0.117^{\star \star \star}$ & $-0.327^{\star \star \star}$ \\
\hline $\mathrm{FCV} \rightarrow \mathrm{GAD}$ & $0.480^{\star \star \star}$ & & $0.480^{\star \star \star}$ \\
\hline \multicolumn{4}{|c|}{ PMH: Positive mental health; FCV: Fear of COVID-19; GAD: Generalized anxiety disorde } \\
\hline$\star \star \star$ Significa & 001 level. & & \\
\hline
\end{tabular}

\section{Discussion}

To our knowledge, this is the first study investigating the role of positive mental health in reducing fear of COVID-19 and general anxiety disorder. It also examines the relationship between positive mental health and preventive behavior. The majority of studies related to mental health issues caused by COVID-19 have focused on negative mental health problems, such as anxiety [42], worry or panic [43], fear [15], feeling of worthlessness [44], boredom and irritability [45], social isolation [46], quarantine experience [47], sleeplessness [48], fear of infection [49], anger and cognitive decline [50], stress of obstructed healthcare [51], and feelings of loss or grief and stigma [52]. Studies on the importance of positive mental health in times of pandemics are scarce. The current study found high average scores of positive mental health and preventive behavior among the respondents.

With 220 million inhabitants, Pakistan is the sixth most populated country in the world. This large population is at high risk of the spread of COVID-19 and, consequently, high mortality, especially among the elderly and those with chronic diseases [53]. The anticipation of these risks, along with an infodemic, may potentially create fear and anxiety among the population. In the aftermath of the COVID-19 outbreak, fear has been observed among populations worldwide [13]. Fear can have devastating effects on individual's mental health [6]. A mental health crisis can cause multiple obstructions to the effective management of the pandemic. A negative mental health status can substantially deteriorate an individual's actions during panic situations, including preventive behavior. This study found moderate average scores of fear of COVID-19 and general anxiety disorder among the respondents.

The results show a significant negative relationship between positive mental health and fear of COVID-19 and general anxiety disorder. Positive mental health can be a protective factor against issues related to mental health [54]. A lack of positive mental health poses a substantial risk of depression and impaired physical health [55]. Positive mental health has shown a significantly positive association with preventive behavior. Large empirical evidence has reported that positive mental health and positive emotions broaden an individual's awareness, encourage productive thoughts and actions, and promote caregiving 
behavior [56, 57]. It can be inferred that positive mental health stimulates preventive behavior among respondents.

Fear of COVID-19 has been positively and significantly correlated with general anxiety disorder. Anxiety and fear were predominantly found among COVID-19 patients in China [58]. Results of another study from Pakistan suggest that fear of COVID-19 is associated with anxiety sensitivity [59]. The results of the current study are also congruent with findings of an online-based survey conducted that found anxiety related to health issues and media use as predictors of fear of COVID-19 [60].

The findings from the hierarchical linear regression show that positive mental health reduces general anxiety, whereas fear of COVID-19 increases it. Moreover, preventive behavior does not explain general anxiety among the respondents. The results of the structural equational modeling also report that positive mental health reduces fear of COVID-19 and general anxiety.

The findings of this study suggest utilizing strategies to enhance positive mental health and contribute to the well-being of people suffering from anxiety and fear during the pandemic. These findings are extremely important with regard to (mental and physical) healthcare workers in order to understand their conditions. Media (print, electronic, and social) can be used to motivate people to take care of their mental health through positive activities, such as social interaction with loved ones, reading books or spiritual coping. Future research could be conducted to examine the impact of positive mental health strategies in reducing fear and anxiety.

\section{Limitations}

One of the major limitations of this study refers to its cross-sectional design, which does not allow for causal interpretations. Furthermore, when interpreting the results, one need to keep in mind that the data have been collected in May 2020, representing the specific conditions at that time. The online-based data collection does not allow to calculate a response rate. In addition, due to the convenience sampling, the study cannot claim any representativeness.

\section{Conclusion}

This study indicates that the general public in Khyber Pakhtunkhwa, Pakistan, has a good level of positive mental health and preventive behavior - despite a moderate level of fear of COVID-19 and anxiety. People with better positive mental health have less fear of COVID-19 and anxiety, while fear contributes to increasing anxiety. Positive mental health also enhances the preventive behavior of individuals during the pandemic. To summarize, positive mental health reduces fear of COVID-19 and general anxiety. Based on these findings, there is a need to develop community health policy emphasizing the devising of positive mental health strategies for people practicing social/physical distancing and isolation. 


\section{Abbreviations}

CFI Comparative fit index

COVID-19 Coronavirus Disease 2019

FCV-19S Fear of COVID-19 Scale

GAD Generalized Anxiety Disorder

GFI Goodness of fit

RMSEA Root mean square error of approximation

RMSR Root mean square residual

SD Standard deviation

SEM Structural equational modeling

WHO World Health Organization

\section{Declarations}

\section{Ethical Approval and Consent to Participate}

We received an ethical approval for this study from the Ethical Review Committee of the Department of Sociology, International Islamic University Islamabad (No. 002-20). Every participant provided onlinebased informed consent. The study was carried our in accordance with all relevant guidelines, such as the Guidelines and Recommendations to Assure Good Epidemiologic Practice published by the German Society for Epidemiology.

\section{Consent for Publication}

Not applicable.

\section{Availability of Data and Materials}

Data is available from corresponding author upon reasonable request.

\section{Competing Interest}

The authors declare that no competing interest exist.

\section{Funding}


This research received no supporting funds from any funding agency in the public, commercial, or not-forprofit sector.

\section{Authors Contributions}

The study was conceptualized by QKM and RZ. QKM was responsible for data collection, supported by MMS and WAQ. QKM, MMS, WAQ, RZ and FF analyzed the data. QKM drafted the manuscript, MMS, WAQ, RZ and FF revised it critically for important intellectual content. All authors reviewed the final version of the manuscript.

\section{Acknowledgements}

We acknowledge support from the German Research Foundation (DFG) and the Open Access Publication Fund of Charité - Universitätsmedizin Berlin.

\section{References}

1. El-Zoghby SM, Soltan EM, Salama HM. Impact of the COVID-19 pandemic on mental health and social support among adult Egyptians. J Community Health. 2020;45(4):689-95.

2. Mortality Analyses. Coronavirus Resource Centre, John Hopkins University. https://coronavirus.jhu.edu/data/mortality. Accessed October 15, 2020.

3. Khose S, Moore JX, Wang HE. Epidemiology of the 2020 pandemic of COVID-19 in the State of Texas: The first month of community spread. J Community Health. 2020;45(4):696-701.

4. Zarocostas J. How to fight an infodemic. Lancet. 2020;395(10225):676.

5. He S, Chen S, Kong L, Liu W. Analysis of risk perceptions and related factors concerning COVID-19 epidemic in Chongqing, China. J Community Health. 2021;46(2):278-85.

6. Taylor S, Landry C, Paluszek M, Fergus TA, McKay D, Asmundson GJ. Development and initial validation of the COVID Stress Scales. J Anxiety Disord. 2020;72:102232.

7. Castillo CC. Analysis of the stress, anxiety and healthy habits in the Spanish Covid-19 confinement. Health Science Journal. 2020;14(2):707.

8. Lee SA. Coronavirus Anxiety Scale: A brief mental health screener for COVID-19 related anxiety. Death Stud. 2020;44(7):393-401.

9. James PB, Wardle J, Steel A, Adams J. Post-Ebola psychosocial experiences and coping mechanisms among Ebola survivors: a systematic review. Trop Med Int Health. 2019;24(6):671-91.

10. Blakey SM, Abramowitz JS. Psychological predictors of health anxiety in response to the Zika virus. J Clin Psychol Med Settings. 2017;24(3-4):270-8.

11. Ji D, Ji YJ, Duan XZ, Li WG, Sun ZQ, Song XA, Meng YH, Tang HM, Chu F, Niu XX, Chen GF, Li J, Duan HJ. Prevalence of psychological symptoms among Ebola survivors and healthcare workers during the 2014-2015 Ebola outbreak in Sierra Leone: a cross-sectional study. Oncotarget. 2017;8(8):12784-91. 
12. Wadoum RG, Samin A, Mafopa NG, Giovanetti M, Russo G, Turay P, Turay J, Kargbo M, Kanu MT, Kargbo B, Akpablie J, Cain CJ, Pasin P, Batwala V, Sobze MS, Potestà M, Minutolo A, Colizzi V, Montesano C. Mobile health clinic for the medical management of clinical sequelae experienced by survivors of the 2013-2016 Ebola virus disease outbreak in Sierra Leone, West Africa. Eur J Clin Microbiol Infect Dis. 2017;36(11):2193-200.

13. Asmundson GJ, Taylor S. Coronaphobia: Fear and the 2019-nCoV outbreak. J Anxiety Disord. 2020;70:102196.

14. Lin CY. Social reaction toward the 2019 novel coronavirus (COVID-19). Social Health and Behavior. 2020;3(1):1.

15. Ahorsu DK, Lin CY, Imani V, Saffari M, Griffiths MD, Pakpour AH. The Fear of COVID-19Sscale: Development and initial validation. Int J Ment Health Addict. 2020; doi:10.1007/s11469-020-002708.

16. Abdulkareem SA, Augustijn EW, Filatova T, Musial K, Mustafa YT. Risk perception and behavioral change during epidemics: Comparing models of individual and collective learning. PloS One. 2020;15(1):e0226483.

17. World Health Organization. Mental health and psychosocial considerations during the COVID-19 outbreak, 18 March 2020. Geneva: World Health Organization; 2020.

18. Vaillant GE. Positive emotions, spirituality and the practice of psychiatry. Mens Sana Monographs. 2008;6(1):48.

19. Lambert C. The science of happiness. Harvard Magazine. 2007;109(3):26.

20. Slade M. Mental illness and well-being: the central importance of positive psychology and recovery approaches. BMC Health Serv Res. 2010;10:26.

21. Keyes CL, Sohail MM, Molokwu NJ, Parnell H, Amanya C, Kaza VG, Saddo YB, Vann V, Tzudier S, Proeschold-Bell RJ. How would you describe a mentally healthy person? A cross-cultural qualitative study of caregivers of orphans and separated children. Journal of Happiness Studies. 2021;22:1719-43.

22. Keyes CL. Mental health as a complete state: How the salutogenic perspective completes the picture. In: Bauer GF, Hämming O (eds.), Bridging Occupational, Organizational and Public Health (pp. 179192). Dordrecht: Springer; 2014.

23. Westerhof GJ, Keyes CL. Mental illness and mental health: The two continua model across the lifespan. Journal Adult Dev. 2010;17(2):110-9.

24. Provencher HL, Keyes CL. Complete mental health recovery: Bridging mental illness with positive mental health. Journal of Public Mental Health. 2011;10(1):57-69.

25. Iasiello M, van Agteren J, Keyes CL, Cochrane EM. Positive mental health as a predictor of recovery from mental illness. J Affect Disord. 2019;251:227-30.

26. Lee Duckworth A, Steen TA, Seligman ME. Positive psychology in clinical practice. Annu Rev Clin Psychol. 2005;1:629-51. 
27. Chi X, Becker B, Yu Q, Willeit P, Jiao C, Huang L, Hossain MM, Grabovac I, Yeung A, Lin J, Veronese N. Prevalence and psychosocial correlates of mental health outcomes among Chinese college students during the coronavirus disease (covid-19) pandemic. Front Psychiatry. 2020;11:803.

28. Choi EP, Hui BP, Wan EY. Depression and anxiety in Hong Kong during COVID-19. Int J Environ Res Public Health. 2020;17(10):3740.

29. Hyland P, Shevlin M, McBride $O$, Murphy J, Karatzias T, Bentall RP, Martinez A, Vallières F. Anxiety and depression in the Republic of Ireland during the COVID-19 pandemic. Acta Psychiatr Scand. 2020;142(3):249-56.

30. Ustun G. Determining depression and related factors in a society affected by COVID-19 pandemic. Int J Soc Psychiatry. 2020; doi: 10.1177/0020764020938807.

31. Insel TR, Scolnick EM. Cure therapeutics and strategic prevention: raising the bar for mental health research. Mol Psychiatry. 2006;11(1):11-7.

32. Provisional Summary Results of 6th Population and Housing Census-2017. . Accessed on 13 January 2021.

33. Khan SA. Situation Analysis of Health Care System of Pakistan: Post 18 Amendments. Health Care Current Reviews. 2019;7(3):244.

34. KPK Cases Details. https://covid.gov.pk/stats/kpk. Accessed on 13 January 2021.

35. Lukat J, Margraf J, Lutz R, van der Veld WM, Becker ES. Psychometric properties of the positive mental health scale (PMH-scale). BMC Psychol. 2016;4:8.

36. Soraci P, Ferrari A, Abbiati FA, Del Fante E, De Pace R, Urso A, Griffiths MD. Validation and psychometric evaluation of the Italian version of the Fear of COVID-19 Scale. Int J Ment Health Addict. 2020; doi: 10.1007/s11469-020-00277-1.

37. Sakib N, Bhuiyan Al, Hossain S, Al Mamun F, Hosen I, Abdullah AH, Sarker MA, Mohiuddin MS, Rayhan I, Hossain M, Sikder MT. Psychometric validation of the Bangla Fear of COVID-19 Scale: Confirmatory factor analysis and Rasch analysis. Int J Ment Health Addict. 2020; doi: 10.1007/s11469-020-00289-x.

38. Tsipropoulou V, Nikopoulou VA, Holeva V, Nasika Z, Diakogiannis I, Sakka S, Kostikidou S, Varvara C, Spyridopoulou E, Parlapani E. Psychometric Properties of the Greek Version of FCV-19S. Int J Ment Health Addict. 2020; doi: 10.1007/s11469-020-00319-8.

39. Mahmood QK, Jafree SR, Qureshi WA. The psychometric validation of FCV19S in Urdu and sociodemographic association with fear in the people of the Khyber Pakhtunkhwa (KPK) province in Pakistan. Int J Ment Health Addict. 2020; doi: 10.1007/s11469-020-00371-4.

40. Spitzer RL, Kroenke K, Williams JB, Löwe B. A brief measure for assessing generalized anxiety disorder: the GAD-7. Arch Intern Med. 2006;166(10):1092-7.

41. Byrne BM, Campbell TL. Cross-cultural comparisons and the presumption of equivalent measurement and theoretical structure: A look beneath the surface. Journal of Cross-Cultural Psychology. 1999;30(5):555-74. 
42. Salman M, Asif N, Mustafa ZU, Khan TM, Shehzadi N, Hussain K, Tahir H, Raza MH, Khan MT. Psychological impact of COVID-19 on Pakistani university students and how they are coping. medRxiv. 2020; doi: 10.1101/2020.05.21.20108647.

43. Fardin MA. COVID-19 and anxiety: A review of psychological impacts of infectious disease outbreaks. Arch Clin Infect Dis. 2020;15(COVID-19):e102779.

44. Chen Q, Liang M, Li Y, Guo J, Fei D, Wang L, He L, Sheng C, Cai Y, Li X, Wang J. Mental health care for medical staff in China during the COVID-19 outbreak. Lancet Psychiatry. 2020;7(4):e15-6.

45. Wang G, Zhang Y, Zhao J, Zhang J, Jiang F. Mitigate the effects of home confinement on children during the COVID-19 outbreak. Lancet. 2020;395(10228):945-7.

46. Zhang Y, Ma ZF. Impact of the COVID-19 pandemic on mental health and quality of life among local residents in Liaoning Province, China: A cross-sectional study. Int I Environ Res Public Health. 2020;17(7):2381.

47. Ho CS, Chee $\mathrm{C}$, Ho R. Mental health strategies to combat the psychological impact of coronavirus disease 2019 (COVID-19) beyond paranoia and panic. Ann Acad Med Singap. 2020;49(3):155-60.

48. Abdulah DM, Musa DH. Insomnia and stress of physicians during COVID-19 outbreak. Sleep Med X. 2020;2:100017.

49. Unadkat S, Farquhar M. Doctors' wellbeing: self-care during the covid-19 pandemic. BMJ;368:m1150.

50. Jiménez-Pavón D, Carbonell-Baeza A, Lavie CJ. Physical exercise as therapy to fight against the mental and physical consequences of COVID-19 quarantine: Special focus in older people. Prog Cardiovasc Dis. 2020;63(3):386-8.

51. Qiu J, Shen B, Zhao M, Wang Z, Xie B, Xu Y. A nationwide survey of psychological distress among Chinese people in the COVID-19 epidemic: implications and policy recommendations. Gen Psychiatr. 2020;33(2):e100213.

52. Kirby T. Efforts escalate to protect homeless people from COVID-19 in UK. Lancet Respir Med. 2020;8(5):447-9.

53. Abdelhafiz AS, Mohammed Z, Ibrahim ME, Ziady HH, Alorabi M, Ayyad M, Sultan EA. Knowledge, perceptions, and attitude of Egyptians towards the novel coronavirus disease (COVID-19). J Community Health. 2020;45(4):881-90.

54. Sambasivam R, Vaingankar JA, Chong SA, Abdin E, Jeyagurunathan A, Seow LS, Pang S, Subramaniam M. Positive mental health in outpatients: comparison within diagnostic groups. BMC Psychiatry. 2016;16:412.

55. Wood AM, Joseph S. The absence of positive psychological (eudemonic) well-being as a risk factor for depression: A ten year cohort study. J Affect Disord. 2010;122(3):213-7.

56. Proeschold-Bell RJ, Molokwu NJ, Keyes CL, Sohail MM, Eagle DE, Parnell HE, Kinghorn WA, Amanya C, Vann V, Madan I, Biru BM. Caring and thriving: An international qualitative study of caregivers of orphaned and vulnerable children and strategies to sustain positive mental health. Children and Youth Services Review. 2019;98:143-53. 
57. Fredrickson BL. The role of positive emotions in positive psychology: The broaden-and-build theory of positive emotions. Am Psychol. 2001;56(3):218-26.

58. Xu K, Cai H, Shen Y, Ni Q, Chen Y, Hu S, Li J, Wang H, Yu L, Huang H, Qiu Y. Management of corona virus disease-19 (COVID-19): the Zhejiang experience. Journal of Zhejiang University (Medical Science). 2020;49(1):147-57.

59. Hongbo L, Waqas MA. Psychological predictors of anxiety in response to the COVID-19 pandemic: Evidence from Pakistan. Psychiatry Investig. 2020;17(11):1096-1104.

60. Mertens G, Gerritsen L, Duijndam S, Salemink E, Engelhard IM. Fear of the coronavirus (COVID-19): Predictors in an online study conducted in March 2020. J Anxiety Disord. 2020;74:102258.

\section{Figures}

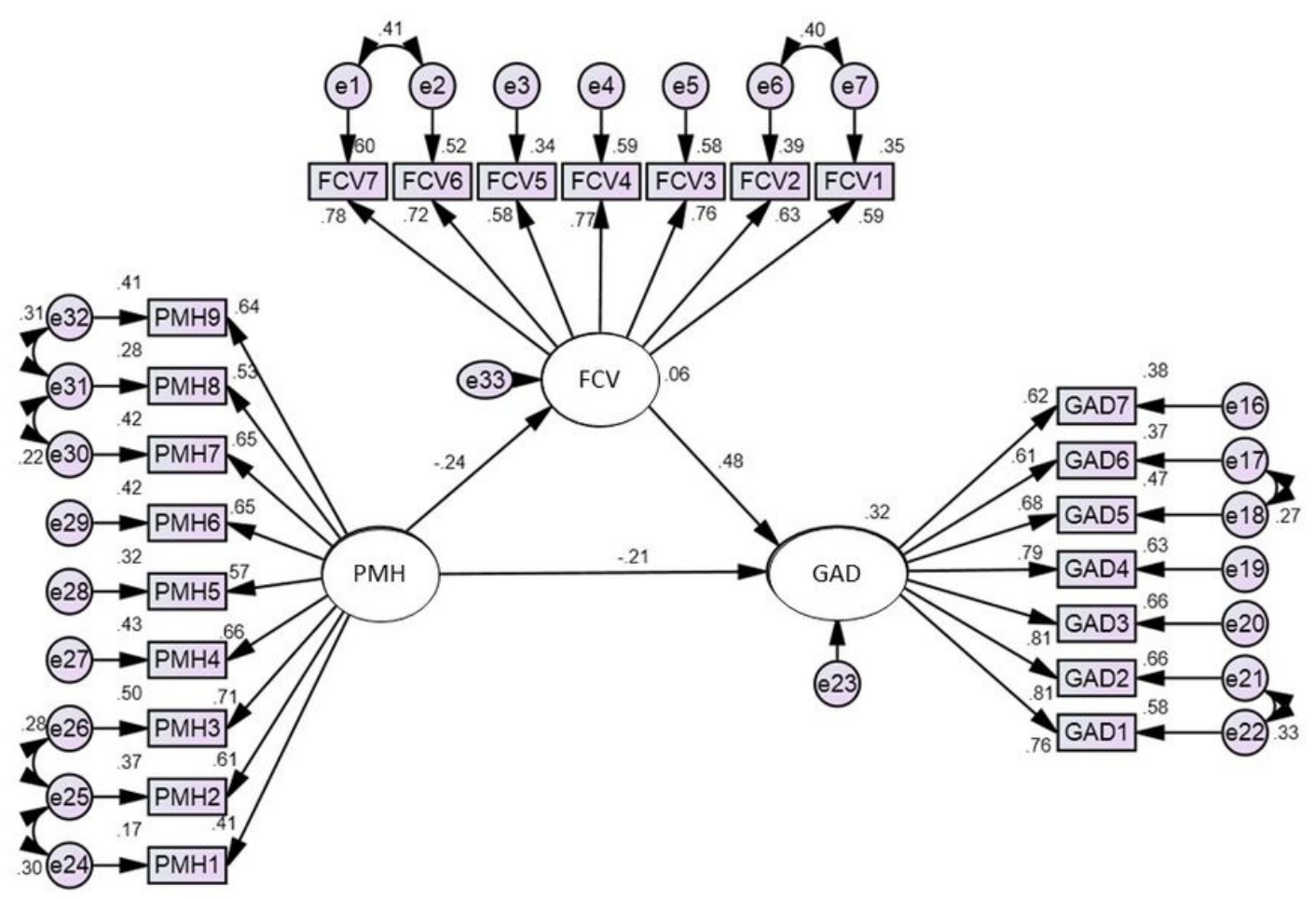

Figure 1

SEM model 